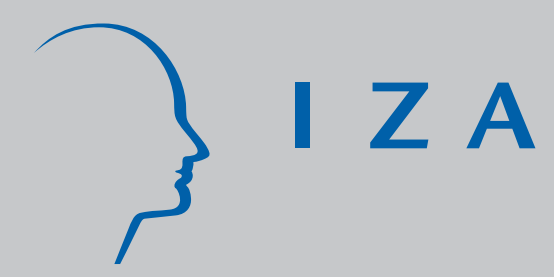

IZA DP No. 1831

Why Are More Redistributive Social Security Systems Smaller? A Median Voter Approach

Marko Köthenbürger

Panu Poutvaara

Paola Profeta

November 2005 


\title{
Why Are More Redistributive Social Security Systems Smaller? A Median Voter Approach
}

\author{
Marko Köthenbürger \\ CES, University of Munich and CESifo \\ Panu Poutvaara \\ University of Helsinki, CEBR, \\ CESifo, HECER and IZA Bonn \\ Paola Profeta \\ Bocconi University
}

\section{Discussion Paper No. 1831 \\ November 2005}

\author{
IZA \\ P.O. Box 7240 \\ 53072 Bonn \\ Germany \\ Phone: +49-228-3894-0 \\ Fax: +49-228-3894-180 \\ Email: iza@iza.org
}

\begin{abstract}
Any opinions expressed here are those of the author(s) and not those of the institute. Research disseminated by IZA may include views on policy, but the institute itself takes no institutional policy positions.

The Institute for the Study of Labor (IZA) in Bonn is a local and virtual international research center and a place of communication between science, politics and business. IZA is an independent nonprofit company supported by Deutsche Post World Net. The center is associated with the University of Bonn and offers a stimulating research environment through its research networks, research support, and visitors and doctoral programs. IZA engages in (i) original and internationally competitive research in all fields of labor economics, (ii) development of policy concepts, and (iii) dissemination of research results and concepts to the interested public.
\end{abstract}

IZA Discussion Papers often represent preliminary work and are circulated to encourage discussion. Citation of such a paper should account for its provisional character. A revised version may be available directly from the author. 
IZA Discussion Paper No. 1831

November 2005

\section{ABSTRACT}

\section{Why are More Redistributive Social Security Systems Smaller? A Median Voter Approach ${ }^{\star}$}

We suggest a political economy explanation for the stylized fact that intragenerationally more redistributive social security systems are smaller. We relate the stylized fact to an "efficiencyredistribution" trade-off to be resolved by political process. The inefficiency of social security financing is due to endogenous labor supply. Using data on eight European countries, we find that the stylized fact and a considerable degree of cross-country variation in contribution rates can be explained by the median voter model.

JEL Classification: H55, D72

Keywords: earnings-related and flat-rate benefits, applied political economy, public pensions, labor supply

Corresponding author:

Panu Poutvaara

Department of Economics

P.O. Box 17 (Arkadiankatu 7)

FIN-00014 University of Helsinki

Finland

Email: panu.poutvaara@helsinki.fi

\footnotetext{
* Comments received at presentations at CES (Munich), CEBR (Copenhagen), Mannheim, Tilburg, at the IIPF meeting in Milan 2004, at the RES meeting in Nottingham 2005, at the CESifo area conference in Munich 2005, at the Norwegian-German Seminar on Public Economics in GarmischPartenkirchen 2005 and at the CEPR/RTN Final conference on "Financing Retirement in Europe" in London 2005 are gratefully acknowledged. In particular, we wish to thank Edmund Cannon, Guenther Fink, Vincenzo Galasso, Michael Hoel and Jean-Marie Lozachmeur for valuable comments. We acknowledge financial support from the Danish Social Science Research Council, without implicating the sponsor for the views expressed.
} 


\section{Introduction}

Old-age pensions are at the core of public sector in almost all OECD countries. In 2001, the 15 EU member states spent on average 8.8 percent of their GDP on public old-age pensions (OECD, 2004). But while united in fiscal importance, pension systems are divided in how benefits are linked to past earnings. In earnings-related ("Bismarckian") public pension programs, pensions are perceived as a form of postponed wage income, intended to replace earnings during retirement. Such benefit rules dominate in Continental Europe, including France, Germany and Italy. In the competing tradition of rather flat-rate ("Beveridgean") pensions, the stated aim of old-age benefits is to guarantee a reasonable standard of living for the elderly, and benefits are correspondingly flat-rate or close to it. Countries with close to flat-rate pensions include Japan, the United Kingdom, and the United States. ${ }^{1}$ Since contributions are typically proportional to earnings, flat-rate benefit formulas imply more intragenerational redistribution than in earnings-related systems.

Countries with earnings-related public pension programs have considerably higher contribution rates than those with flat-rate benefits. Disney (2004) reports that the effective contribution rates in the 10 OECD countries dominated by flat-rate systems varied between 14,7 percent in Australia and 23,7 percent in the United Kingdom in 1995. The range in the 12 OECD countries with more earnings-related benefits was between 22,4 percent in Germany and 57,7 percent in Greece. The average effective contribution rate was 19 percent in countries with flat-rate benefits, and 35 percent in countries with earnings-related benefits. ${ }^{2}$

In this paper, we analyze to what extent the stylized fact can be reconciled by a "efficiencyredistribution" trade-off about which the political process compromises. In particular, we ask whether a median voter model is able to explain the positive correlation between the size of the social security system and the degree to which pension benefits depend on past contributions. We first present a theoretical model where citizens vote on the social security contribution rate in the presence of endogenous labor supply. Citizens differ in two dimensions, age and productivity. There are three cohorts, the young, the middle-aged and the old, and five productivity classes within each cohort. Social security benefits encompass an earnings-related and flat-rate component. As contributions towards earnings-related benefits cause smaller labor supply distortions, the efficiency cost of social security financing is lower the smaller the redistributive flat-rate pillar. Thus, the correlation between the size of social security and the degree to which pensions are earnings-related depends on the age and productivity of the politically-decisive voter.

In a second step, we perform a numerical analysis that delivers the political equilibrium social security contribution rates for Austria, France, Germany, Greece, Italy, Portugal, Spain and the United Kingdom. The numerically solved median voter model predicts that countries with more earnings-related public pension programs vote for a higher contribution rate than those with more flat-rate benefits - a prediction which is in line with the stylized fact.

Although being a cornerstone in economic policy reasoning, the trade-off between efficiency

\footnotetext{
${ }^{1}$ In most countries, social security has both a flat-rate and an earnings-related component, the relative importance of which differs. We choose labels for countries according to which component is more pronounced, taking our classification from Disney (2004) who labels earnings-related systems Bismarckian and flat-rate systems Beveridgean.

${ }^{2}$ In 2001, public spending on old-age benefits was in average 6,4 percent of GDP in countries with flat-rate benefits, and 9,4 percent in countries with earnings-related benefits (Disney, 2004; OECD, 2004).
} 
and equity has (surprisingly for us) not been invoked in rationalizing why earnings-related systems are larger. The political economy literature has mainly focused on explaining the aggregate size of social security (proxied by the contribution rate). Therein benefits are usually assumed to be either perfectly flat-rate or earnings-related (see Galasso and Profeta (2002), Mulligan and Sala-i-Martin (2004) for surveys and the seminal contributions by Browning (1975), Boadway and Wildasin (1989), Cooley and Soares (1999), Tabellini (2000) and Boldrin and Rustichini (2000)). An explanation for the stylized fact which relies on borrowing constraints has been proposed by Casamatta et al. (2000). Our motivation for testing the role of labor supply distortions rather than the role of borrowing constraints in explaining the correlation derives from the observation that in particular young, low-productivity individuals face borrowing constraints. Analyses of voting behavior suggest that the politically decisive voter is advanced in age and not necessarily of low-income (e.g. Cooley and Soares, 1999 and Sinn and Uebelmesser, 2002) - a household type for which borrowing constraints play a diminished role. Thus, in our paper capital markets are perfect and, to capture the role of age for voting behavior more thoroughly, individuals work for two periods. The latter difference entails that even high-productivity individuals tend to support social security. When close to retirement, they view past contributions as sunk and prefer a continuation of social security (Cooley and Soares, 1999 and Boldrin and Rustichini, 2000).

Conde-Ruiz and Profeta (2004) analyze simultaneous voting on the type of social security system and on its size. In their model, a smaller flat-rate system is supported by a voting coalition of low-income individuals, who are in favor of a redistributive system, and highincome individuals, who are in favor of a redistributive system provided that the social security contribution rate is smaller, so that they can invest their resources in the private capital market, where they can earn higher returns. A large earnings-related system instead is supported by the middle-income individuals. Different to our paper, Conde-Ruiz and Profeta (2004) take labor supply to be exogenous. We show that labor supply distortions are sufficient to explain the positive relationship between the degree of intragenerational redistribution and the size of the social security system. As a consequence of our one-dimensional voting approach, our explanation applies also to countries where the type of social security (earnings-related or flatrate) has been historically given. Also, we test our model by performing a numerical analysis, calibrated on income distribution and social security rules in different European countries. To the best of our knowledge, there exists no previous median voter analysis which empirically relates cross-country differences in social security contribution rates to the redistributiveness of social security.

Our paper is organized as follows. Section 2 presents our theoretical model. Section 3 presents the numerical analysis and Section 4 concludes.

\section{The Model}

\subsection{Economy}

Individuals differ in two dimensions: age and productivity. In each period there are three overlapping generations: young, middle-aged and old. Each generation works for two periods, 1 and 2, and is retired in period 3. Individuals of each cohort differ in their productivity. We index the productivity types so that the productivity is increasing in the index number, the 
lowest productivity being denoted by one. While our theoretical framework holds with any number $J$ of productivity types, we restrict the number of productivity classes to five in each age group in the numerical part of the paper. The induced productivity is allowed to vary over the life-cycle. The productivity of a $j$-type individual, being young in period $t$ is denoted as $a_{j, t}^{y}>0$. The productivity of a $j$-type individual who is middle-aged in period $t$ is analogously denoted as $a_{j, t}^{m}>0$. All productivity parameters grow at the rate $g$. The number of workers being of a $j$ type born in period $t$ is $n_{j, t}$, with the total size of the age-cohort born in period $t$ being $\sum_{j} n_{j, t}=n_{t}$. For simplicity, the proportion of each productivity type in the population stays constant over time, i.e. $\frac{n_{j, t}}{n_{t}}=\frac{n_{j, t+1}}{n_{t+1}}$. The cohort size evolves according to $n_{t+1}=(1+\eta) n_{t}$.

Preferences are given by a well-behaved utility function $U=u\left(c_{j, t}^{y}, c_{j, t+1}^{m}, c_{j, t+2}^{o}\right)$ defined over consumption when being young, middle-aged and old. Consumption of a $j$-type individual born in period $t$ is

$$
\begin{aligned}
c_{j, t}^{y} & =\left(1-\tau_{t}-\tau_{w}\right) a_{j, t}^{y} l_{j, t}^{y}-v\left(a_{j, t}^{y}, l_{j, t}^{y}\right)-s_{j, t}^{y}, \\
c_{j, t+1}^{m} & =\left(1-\tau_{t+1}-\tau_{w}\right) a_{j, t+1}^{m} l_{j, t+1}^{m}-v\left(a_{j, t+1}^{m}, l_{j, t+1}^{m}\right)+(1+r) s_{j, t}^{y}-s_{j, t+1}^{m} \text { and } \\
c_{j, t+2}^{o} & =p_{j, t+2}+(1+r) s_{j, t+1}^{m} .
\end{aligned}
$$

$l_{j, t}^{y}\left(l_{j, t}^{m}\right)$ denotes working hours by a $j$-type individual being young (middle-aged) in period $t$ which gives a gross wage income $a_{j, t}^{y} l_{j, t}^{y}\left(a_{j, t}^{m} l_{j, t}^{m}\right)$. Without loss of generality the wage rate each $j$-type individual receives per efficiency unit of labor supply, $a_{j, t}^{y} l_{j, t}^{y}$, is normalized to unity. In the first period of life an individual of $j$-type derives utility from private consumption $c_{j, t}^{y}$ which is the net wage income, $\left(1-\tau_{t}-\tau_{w}\right) a_{j, t}^{y} l_{j, t}^{y}$, minus the monetarized disutility of labor supply, $v\left(a_{j, t}^{y}, l_{j, t}^{y}\right)$, and private savings $s_{j, t}^{y} \cdot{ }^{3} \tau_{t}$ and $\tau_{w}$ are the social security contribution rate and the general wage tax rate. The cost of labor supply $v(\cdot)$ is continuous, strictly increasing and convex in $l_{j, t}^{y}$ and $l_{j, t+1}^{m}$, respectively. An analogous structure applies to consumption in the second period of life. Old age consumption, $c_{j, t+2}^{o}$, is financed out of pension payments, $p_{j, t+2}$, and private savings, $(1+r) s_{j, t+1}^{m}$, where $r$ denotes the interest rate. There are no bequests.

Product and factor markets are perfectly competitive and market prices are exogenous for the economy. The fixity of prices may follow from a linear production technology or in a small open economy from factor price equalization in the presence of goods traded. ${ }^{4}$

\subsection{Social Security System}

We consider a pay-as-you-go (PAYG) social security system. Thus, total pension payments in period $t+2, P_{t+2}$, equal contributions collected from the young and middle-aged in the same $\operatorname{period}^{5}$ :

$$
P_{t+2}=\tau_{t+2}\left(\sum_{j} n_{j, t+2} a_{j, t+2}^{y} l_{j, t+2}^{y}+\sum_{j} n_{j, t+1} a_{j, t+2}^{m} l_{j, t+2}^{m}\right) .
$$

\footnotetext{
${ }^{3}$ Modelling the disutility from labor supply as a reduction in instantaneous consumption is common in analyses of welfare programs, see e.g. Saez (2002) and Immervoll et al. (2004). An important implication of this modelling choice is that all income effects are shifted onto consumption demand.

${ }^{4}$ In this way, intergenerational linkages are exclusively formed by the unfunded social security system.

${ }^{5}$ Notice that individuals pay a unique social security tax rate (not two, one for the earnings-related part and one for the flat-rate part of the social security system).
} 
The individual pension payment in period $t+2$ consists of a flat-rate and an earnings-related component:

$$
p_{j, t+2}=\bar{p}_{t+2}+b_{j, t+2} .
$$

In the earnings-related component, the benefit $b_{j, t+2}$ is indexed to wage income in period $t+1$ and $t$ according to the formula

$$
b_{j, t+2}=\theta\left(x_{t+2}^{y} a_{j, t}^{y} l_{j, t}^{y}+x_{t+2}^{m} a_{j, t+1}^{m} l_{j, t+1}^{m}\right) .
$$

$\theta x_{t+2}^{y}$ and $\theta x_{t+2}^{m}$ denote how income as young and middle-aged translate into pension claims in period $t+2$. The proportionality factors decompose into time-specific factors, $x_{t+2}^{y}$ and $x_{t+2}^{m}$, potentially allowing income earned as young and middle-aged to be treated differently in the pension formula, and a time-independent factor, $\theta$, frequently referred to as the Bismarckian index. Straightforwardly, $\theta x_{t+2}^{y}$ and $\theta x_{t+2}^{m}$ are zero in pure flat-rate system $(\theta=0)$ and are largest (ceteris paribus) in a pure earnings-related system $(\theta=1)$. The pension formula $(6)$ fixes how the pension payment is related to the income history, but leaves it unspecified how one euro collected in period $t$ (and devoted to the earnings-related pillar) is spent on pension claims gathered when being young and middle-aged. To fill the gap we assume that the link between income in the first and second period of life and pension claims satisfies

$$
x_{t+i}^{y}=x_{t+i}^{m}(1+r) .
$$

Residually determined, the flat-rate component $\bar{p}_{t+2}$ is

$$
\bar{p}_{t+2}=(1-\theta) \frac{P_{t+2}}{n_{t}} .
$$

\subsection{Economic Equilibrium}

We solve the model for the constant-elasticity specification

$$
v\left(a_{j, t}^{i}, l_{j, t}^{i}\right)=\frac{\gamma}{1+\gamma} a_{j, t}^{i} l_{j, t}^{i \frac{1+\gamma}{\gamma}}, \quad \gamma>0, \quad i=y, m .
$$

$\gamma^{-1}$ is the elasticity of marginal disutility with respect to labor supply $l_{j, t}^{i}$. The disutility of labor supply positively depends on the individuals' productivity which captures the idea that high income households face a higher opportunity cost of labor supply. Individual labor supply and saving decisions in the first and second period follow from

$$
\max _{l_{j, t}^{y}, l_{j, t+1}^{m}, s_{j, t}^{y}, s_{j, t+1}^{m}} U=u\left(c_{j, t}^{y}, c_{j, t+1}^{m}, c_{j, t+2}^{o}\right) \quad \text { s.t. (1) to (3), (5), and (6). }
$$

The individual first-order conditions can be written as

$$
\begin{aligned}
l_{j, t}^{y}: & \frac{\partial u}{\partial c_{j, t}^{y}}\left(\left(1-\tau_{t}-\tau_{w}\right) a_{j, t}^{y}-\frac{\partial v\left(a_{j, t}^{y}, l_{j, t}^{y}\right)}{\partial l_{j, t}^{y}}\right)+\frac{\partial u}{\partial c_{j, t+2}^{o}} \theta x_{t+2}^{y} a_{j, t}^{y}=0 \\
l_{j, t+1}^{m}: & \frac{\partial u}{\partial c_{j, t+1}^{m}}\left(\left(1-\tau_{t+1}-\tau_{w}\right) a_{j, t+1}^{m}-\frac{\partial v\left(a_{j, t+1}^{m}, l_{j, t+1}^{m}\right)}{\partial l_{j, t+1}^{m}}\right)+\frac{\partial u}{\partial c_{j, t+2}^{o}} \theta x_{t+2}^{m} a_{j, t+1}^{m}=0 \\
s_{j, t}^{y}: & -\frac{\partial u}{\partial c_{j, t}^{y}}+\frac{\partial u}{\partial c_{j, t+1}^{m}}(1+r)=0 \text { and } s_{j, t+1}^{m}:-\frac{\partial u}{\partial c_{j, t+1}^{m}}+\frac{\partial u}{\partial c_{j, t+2}^{o}}(1+r)=0
\end{aligned}
$$


With the help of auxiliary variable $\chi$, which is defined in the appendix and is independent of the contribution rate, we can prove:

Lemma 1 Keeping $\tau_{t}$ constant $\left(\tau_{t+i}=\tau_{t}\right)$, the economy has a balanced growth path in which the individual labor supply in each working period is

$$
\widehat{l\left(\tau_{t}\right)}=\left[1-\tau_{w}-\tau_{t}\left(1-\frac{\theta \chi}{1+r}\right)\right]^{\gamma}
$$

and the social security system offers as rates of return

$$
x_{t+i}^{y}=\tau_{t} \chi(1+r) \text { and } x_{t+i}^{m}=\tau_{t} \chi .
$$

$\chi$ measures the ratio of total wage income out of which pension benefits are financed in $t+2$ over the aggregate life-cycle income of the contributors of the same age-cohort discounted to the second period of life $t+1$.

In what follows we consider the case of a dynamically-efficient economy. Thus, we find:

Lemma 2 In a dynamically efficient economy, $\chi$ is lower than $1+r$.

Labor supply is downward distorted by the general wage tax $\tau_{w}$. The negative impact of the social security contribution rate $\tau_{t}$ due to a reduction in wage income is counteracted by the link between income and pension claims $\theta \chi$. Implied by Lemma 2 the fraction of the contribution rate which is considered a wage tax, $1-\frac{\theta \chi}{1+r}$, is strictly positive for $\theta \in[0,1]$. Evident from (14) labor supply is thus decreasing in the contribution rate where the distortion magnifies as $\gamma$ increases.

To clarify the implications of assumptions (7) and (9) for labor supply behavior, note that the uniformity only applies to working time. Labor supply in efficiency units is heterogeneous for different productivity types of the same cohort and over the life-cycle if individual productivity changes over time. Individual preferences for social security are heterogeneous along both the productivity and age dimension.

\section{$3 \quad$ Political Equilibrium}

As voters, citizens not only evaluate the impact of social security on their individual labor supply, but also evaluate how the PAYG budget is affected by a change in the contribution rate. Voting over the contribution rate takes place given the type of the social security system measured by $\theta .{ }^{6}$ In order to focus on issues arising in voting on social security we take $\tau_{w}$ as given. Citizens decide upon the social security contribution rate by a once-and-for-all voting. The identified political equilibrium can also be sustained in a repeated voting setting by resorting to a suitable trigger strategy, see Koethenbuerger et al. (2005).

Formally, a $j$-type voter young in period $t$ maximizes:

$$
\begin{aligned}
& u\left(\widehat{c_{j, t}^{y}}, \widehat{c_{j, t+1}^{m}}, \tau_{t} \theta \chi\left((1+r) a_{j, t}^{y}+a_{j, t+1}^{m}\right) \widehat{l\left(\tau_{t}\right)}+\frac{1-\theta}{n_{t}} P_{t+2}+(1+r) \widehat{s_{j, t+1}^{m}}\right) \\
& \text { s.t. } \quad(1) \text { to }(3),(4),(14) \text { and (11) to (13). }
\end{aligned}
$$

\footnotetext{
${ }^{6}$ Similar to Casamatta et al. (2000), the voting game is one-dimensional, since we assume that the type of social security is more stable over time than the contribution rate, which may well adjust annually.
} 
Variables with $\mathrm{a}^{-}$denote the optimal consumer choices derived from the household optimization problem analyzed in the previous section. Young voters compare the costs arising from social security contributions, made as young and middle-aged, to the benefits they receive as old.

Similarly, a $j$-type voter middle-aged in period $t$ maximizes remaining life-time utility:

$$
\begin{aligned}
& u\left(\widehat{c_{j, t-1}^{y}}, \widehat{c_{j, t}^{m}}, \tau_{t} \theta \chi\left((1+r) a_{j, t-1}^{y}+a_{j, t}^{m}\right) \widehat{l\left(\tau_{t}\right)}+\frac{1-\theta}{n_{t-1}} P_{t+1}+(1+r) \widehat{s_{j, t}^{m}}\right) \\
& \text { s.t. } \quad(2) \text { to }(3),(4),(14) \text { and (12) to (13). }
\end{aligned}
$$

For the middle-aged, contributions made when young are sunk. They just compare the cost arising from social security contributions, made as middle-aged, to the benefits they receive as old.

For any $\theta \in[0,1]$, the benefit each pensioner receives is increasing in the social security budget. The elderly thus uniformly maximize utility by voting for the contribution rate $\arg \max P_{t}$.

The next proposition gives a characterization of how $\gamma, \tau_{w}$ and the degree of intragenerational redistribution $\theta$ influence voting incentives.

Proposition 1 (i) For any given $\theta \in[0,1]$, the preferred contribution rate of young, middleaged, and old voters is weakly decreasing in $\gamma$ and $\tau_{w}$.

(ii) The young and middle-aged voters' preferred contribution rate may be non-monotonic in $\theta \in[0,1]$ provided it is positive. The pensioners' preferred contribution rate is weakly increasing in $\theta \in[0,1]$.

Increases in $\gamma$ and $\tau_{w}$ encourage voting for a lower social security contribution rate as both increase the efficiency cost of social security financing. Earnings-related and flat-rate social security components generate different voting incentives to the young and middle-aged voters of different ability types. In a pure earnings-related social security system $(\theta=1)$ young voters prefer a zero contribution rate. The rationale is that an earnings-related pension system implicitly taxes contributions at a rate $1-\frac{\chi}{1+r}>0$ in a dynamically efficient economy - see Lemma 2. The young would prefer to eliminate the implicit tax burden by voting for a zero contribution rate. If the continuation benefit outweighs the implicit taxation of the second period's contribution, the middle-aged will vote for a positive contribution rate. In a pure flat-rate system $(\theta=0)$, on the other hand, the coalition supporting social security generally crosses different cohorts. High-income young and middle-aged individuals may jointly vote for a lower contribution rate than e.g. low-income young and middle-aged individuals. In a mixed system $\theta \in(0,1)$ voting incentives tend to be a convex combination of voting incentives in the polar cases.

A marginal increase of the earnings-related component of social security $\theta$ has two effects: it reduces the efficiency cost of social security financing at the expense of less intragenerational redistribution. For instance, provided that the politically decisive voter is middle-aged and does not have a very low income, the net effect is that a higher $\theta$ results in a higher social security contribution rate. Since the elderly uniformly vote for the contribution rate $\arg \max P_{t}$ a higher $\theta$ unambiguously increases their preferred contribution rate.

Preferences are single-peaked which renders the median voter politically decisive with majority voting on the contribution rate. 


\section{A Numerical Analysis}

In this section we numerically compute the political-equilibrium social security contribution rates for a sample of European countries. Restricted by data availability, the sample includes: Austria, France, Germany, Greece, Italy, Portugal, Spain and the United Kingdom. ${ }^{7}$

Each country's population is decomposed into three age groups and five income groups. For each of these countries, we numerically solve for the social security contribution rate preferred by each individual in each age and income group and subsequently identify the median voter. Formally, we solve for the optimal choice of $\tau$ for each individual in each age and income group, applying country-specific values for the exogenous variables $\left(\varepsilon, r, \theta, \eta, g, \tau_{w}\right)$.

We simulate the equilibrium social security contribution rate using current data for population and productivity growth rate in each country (see table 1). Parameter values are inferred from past performance during the last period of 20 years.

\subsection{The Data}

We consider three age-groups: young (aged between 21 and 40 years), middle-aged (aged between 41 and 60 years), old (aged between 61 and 80 years), and five income-groups of equal size (very-low income, low-income, intermediate-income, high-income, very-high income). Considering groups of equal size represents a "neutral" criterion to divide the population in the same way in five income groups in all countries.

The data on the current population growth rate are taken from the European Community Household Panel (ECHP), wave 1997. ${ }^{8}$ We calculate the number of individuals in each of the three age groups, and obtain the dependency ratio, defined as the ratio between the number of old individuals and the sum of young and middle-aged individuals. Calling $\xi$ the growth rate of population over one period, consisting of 20 years, the dependency ratio is equal to: $1 /[(1+\xi)(2+\xi)]$, from which we can implicitly derive the value of $\xi$. Calling $\eta$ the annual population growth rate and given that $(1+\eta)^{20}=(1+\xi)$, we derive the value of $\eta$ shown in table 1.

From the ECHP data set, we obtain data on productivity (wage earnings divided by the number of hours worked) for each worker (young and middle-aged). For these two age groups, we divide individuals in 5 income groups of equal size and calculate the average productivity in each income group. We then calculate the overall average productivity for all young and middle-aged. By dividing the average productivity in each income/age group by the overall average productivity, we find the "productivity matrix" for each country, as shown in table 2. Rows correspond to age groups (young, middle-aged) and columns to income groups (very-low income, low-income, intermediate-income, high-income, very-high income).

We approximate $g$, the growth rate of average productivity, by the EUROSTAT data on the average growth rate of per capita productivity in the period 1990-2003. The estimated value of $g$ is used to infer the earnings history of the currently middle-aged cohort from the earnings of the current young cohort.

\footnotetext{
${ }^{7}$ The data are taken from the European Commission Household Panel (ECHP). From the ECHP sample we exclude Belgium, Denmark, Ireland, and the Netherlands because we do not have all necessary information and Luxembourg, Finland, and Sweden because we have too few observations.

${ }^{8}$ For a detailed description of the ECHP data see Nicoletti and Peracchi (2001).
} 
Data on the tax rate on income without social security $\tau_{w}$ (see table 1) are taken from OECD Taxing Wages (2000) and refer to the average tax rate for a single person with no children earning average income.

The value of $\theta$ is calculated as one minus the progressivity index of pension benefit formulae obtained in OECD (2005) using microeconomic projections ${ }^{9}$.

\subsection{The Results}

Our numerical simulations deliver a matrix of preferred contribution rates by age and income group. We aggregate preferences through majority voting, by identifying the median voter and his preferred tax rate. The results are summarized in table 3.

In our simulations, the median voter is always a high-income middle-aged individual, except in Italy and Germany where he is a very-high income middle-aged. In line with the theoretical analysis, we obtain a negative relation between the general wage $\operatorname{tax} \tau_{w}$ and the equilibrium contribution rate $\tau$ (Proposition 1).

The most interesting result relates to the role of the earnings-related component of the pension system $\theta$. The simulation reveals a positive correlation between $\theta$ and the equilibrium social security contribution rate $\tau$ taking the value of $\sim 0.87$ (both when $\gamma=2$ and $\gamma=1.5$ ). The rationale is that the median voter's preferred contribution rate is most likely increasing in $\theta$. Reduced intra-generational redistribution makes social security more attractive to high-income middle-aged individuals, at the same time as it reduces its efficiency cost.

In table 3 we also report the correlations between our simulated contribution rate and the real (effective) contribution rate calculated by Disney (2004) - see table 1. The last line of table 3 shows that our model performs quite well in explaining the real contribution rates. The correlations between real (effective) values and our estimated values range from 0.9 (when $\gamma=2$ ) to 0.91 (when $\gamma=1.5) .{ }^{10}$

We have performed sensitivity analysis with respect to the Bismarckian index $\theta .{ }^{11}$ Based on ECHP data on wages and public pensions Conde Ruiz and Profeta (2004) compute the Bismarckian index as the correlation between the level of post-retirement pension benefit (excluding occupational pensions $)^{12}$ and pre-retirement earnings. Theoretically, in a pure flat-rate

\footnotetext{
${ }^{9}$ The OECD index of progressivity is calculated as $100 \%$ minus the ratio of the Gini coefficient of pension entitlements (considering only considers only mandatory parts of public pension programs) divided by the Gini coefficient of earnings (expressed as percentages). Thus, one minus this index represents a synthetic measure of the degree of redistributiveness of public pension programs.

${ }^{10}$ Calibrating $\gamma$ is inherently difficult. Note, given (14) $\gamma$ is the elasticity of labor supply w.r.t. an increase in the disounted net-of-tax income where income comprises wage income and pension payments, i.e. $\gamma=$ $\frac{\partial l\left(\tau_{t}\right)}{\partial\left(1-\tau_{w}-\tau_{t}\left(1-\frac{\theta \chi}{1+r}\right)\right)} \frac{1-\tau_{w}-\tau_{t}\left(1-\frac{\theta \chi}{1+r}\right)}{l\left(\tau_{t}\right)}>0$. In our model the labor supply elasticity w.r.t. instantaneous income (which is typically estimated in econometric analysis of labor supply behavior) is thus well below $\gamma$. Also, since in the simulation analysis $\gamma$ relates to the labor supply elasticity over a time span of 20 years, in which intensive and extensive labor supply decisions are made (Krueger and Meyer, 2002, and Immervoll et al., 2004), matching $\gamma$ with a empirical labor supply elasticity is notoriously diffícult. However, we should note that we tested other values of $\gamma$ for which the positive correlation between $\theta$ and the equilibrium social security contribution rate $\tau$ prevailed at nearly the same level.

${ }^{11}$ The detailed results are not reported in table 3. They are available upon request.

${ }^{12}$ Occupational pension systems constitute the second pillar of old-age security whose financial importance significantly varies across countries. All firm-based systems are run on a funded basis (Fenge et al., 2003) and in our setting are equivalent to private savings. The Bismarckian index thus need not, and should not, include
} 
system the correlation is zero and unity in an earnings-related system. The simulation shows a correlation between $\theta$ and the equilibrium social security contribution rate $\tau$ of 0.88 and a correlation between the simulated contribution rate and the real (effective) contribution rate of 0.91 (when $\gamma=2$ and $r=0.45$ ).

\section{Concluding Remarks}

The relationship between the level to which benefits depend on past earnings and social security contribution rate has received little attention in the political economy literature, despite its robustness. In this paper, we suggest an explanation based on a standard trade-off between economic efficiency and redistribution. The efficiency cost of redistributing income is lower when benefits are earnings-related, encouraging voters who benefit from social security to support higher contribution rates. Low income voters weigh this effect against the reduced redistributiveness of more earnings-related systems. Our numerical analysis of several European countries suggests that the median voter model is able to explain the stylized fact that intragenerationally more redistributive social security systems are smaller.

The social security contribution rates predicted by the median voter model also have a strong correlation with the effective rates calculated by Disney (2004). This means that our median voter model is able at least in part to explain the levels of contribution rates and their cross-country differences. Even though our analysis focuses on steady-state political equilibria, our main result that benefit formula significantly affects political equilibrium contribution rates can be expected to hold also outside of steady-states. This suggests that the political response to population aging may crucially depend on to what extent benefits are linked to past contributions. Accounting for the dynamic responses is left for future research.

\section{Appendix}

\section{Proof of Lemma 1.}

We first define three auxiliary variables

$$
\begin{aligned}
& \lambda^{y}=\sum_{k} a_{k, 0}^{y} n_{k, 0}, \lambda^{m}=(1+g) \sum_{k} a_{k, 0}^{m} n_{k, 0}, \\
& \chi=\frac{\lambda^{y}(1+\eta)^{2}(1+g)^{2}+\lambda^{m}(1+\eta)(1+g)}{\lambda^{m}+(1+r) \lambda^{y}} .
\end{aligned}
$$

By the assumption of a balanced growth path, the rate of return offered by the PAYG system stays constant over time. Then $x_{t+2+i}^{y}=x_{t+2}^{y}$ and $x_{t+i}^{m}=x_{t+i+1}^{m} \forall i \in\{0,1,2, \ldots\}$. Denote these steady-state values by $x^{y}$ and $x^{m}$. By $(7), x^{y}=(1+r) x^{m}$. (9) and the first-order conditions (11) to (13) then imply

$$
\widehat{l\left(\tau_{t+i}\right)}=\left[1-\tau_{w}-\tau_{t}\left(1-\frac{\theta x^{y}}{1+r}\right)\right]^{\gamma}
$$

occupational pensions. 
As the labor supply is constant over time, so must be the share of PAYG benefits that go to pay for benefit claims earned as young and middle-aged, respectively. Denote the share of earnings-related PAYG benefits that goes to pay for the benefit claims accumulated as young (middle-aged) by $\theta^{y}\left(\theta^{m}\right)>0$. As the total share of earnings-related benefits is $\theta$, this implies that

$$
\theta^{y} \theta P_{t+2}=\theta x^{y} \lambda^{y}(1+\eta)^{t}(1+g)^{t} \widehat{l\left(\tau_{t}\right)}
$$

Analogously,

$$
\theta^{m} \theta P_{t+2}=\theta x^{m} \lambda^{m}(1+\eta)^{t}(1+g)^{t} \widehat{l\left(\tau_{t}\right)}
$$

Dividing (A.2) by (A.3) yields

$$
\frac{\theta^{y}}{\theta^{m}}=\frac{(1+r) \lambda^{y}}{\lambda^{m}}
$$

As $\theta^{y}+\theta^{m}=1$, we have

$$
\theta^{y}=\frac{(1+r) \lambda^{y}}{\lambda^{m}+(1+r) \lambda^{y}} \text { and } \theta^{m}=\frac{\lambda^{m}}{\lambda^{m}+(1+r) \lambda^{y}} .
$$

Inserting this into (A.2) and (A.3) yields $x^{y}=\tau_{t} \chi(1+r)$ and $x^{m}=\tau_{t} \chi$. The proof is completed by noting that these are identical to the values postulated in Lemma 1 . Thus Lemma 1 indeed postulates a balanced growth path of the economy.

Proof of Lemma 2.

Inserting the expression for $\chi$ - see (A.1) - in the inequality $\chi-1<r$ and rearranging gives

$$
(1+\eta)^{2}(1+g)^{2} \lambda^{y}+(1+\eta)(1+g) \lambda^{m}<(1+r)^{2} \lambda^{y}+(1+r) \lambda^{m} .
$$

If the economy is dynamically efficient, $(1+\eta)(1+g)<1+r$, the inequality holds.

\section{Proof of Proposition 1.}

(i) Differentiating (14) w.r.t. $\tau_{t}$ gives

$$
\frac{d l\left(\tau_{t}\right)}{d \tau_{t}}=-\frac{1-\frac{\theta \chi}{1+r}}{\left[1-\tau_{w}-\tau_{t}\left(1-\frac{\theta \chi}{1+r}\right)\right]^{1-\gamma}} \gamma<0 .
$$

In the proof we repeatedly make use of the auxiliary variable

$$
\omega_{t+i}=\lambda^{y}(1+\eta)^{t+i}(1+g)^{t+i}+\lambda^{m}(1+\eta)^{t+i-1}(1+g)^{t+i-1}, \quad i \in \mathbb{N} .
$$

For $\tau_{t+i}=\tau_{t} \forall i \in \mathbb{N}$ (once-and-for-all voting), the contribution rate preferred by a young, $j$-type voter is solved as follows. First, differentiate (15) subject to (1) - (3), (4), and (14). Using the envelope theorem, multiplying by $1 / \widehat{l\left(\tau_{t}\right)}$, and inserting (A.4) yields

$$
\left(-a_{j, t}^{y}-\frac{a_{j, t+1}^{m}}{1+r}\right)\left(1-\frac{1}{1+r} \theta \chi\right)+\frac{1-\theta}{n_{t}(1+r)^{2}}\left(1-\tau_{t} \frac{1-\frac{\theta \chi}{1+r}}{1-\tau_{w}-\tau_{t}\left(1-\frac{\theta \chi}{1+r}\right)} \gamma\right) \omega_{t+2}
$$


By (A.5) and the non-negativity constraint, the preferred contribution rate of the young voters belonging to the ability group $j$ is given by

$$
\tau_{j, t}^{y}=\max \left\{\frac{\left(1-\tau_{w}\right)}{\left(1-\frac{\theta \chi}{1+r}\right)} \frac{\left(-a_{j, t}^{y}-\frac{a_{j, t+1}^{m}}{1+r}\right)\left(1-\frac{1}{1+r} \theta \chi\right) \frac{n_{t}(1+r)^{2}}{(1-\theta) \omega_{t+2}}+1}{\left(-a_{j, t}^{y}-\frac{a_{j, t+1}^{m}}{1+r}\right)\left(1-\frac{1}{1+r} \theta \chi\right) \frac{n_{t}(1+r)^{2}}{(1-\theta) \omega_{t+2}}+1+\gamma}, 0\right\} .
$$

Analogously, for $\tau_{t+i}=\tau_{t} \forall i \in \mathbb{N}$ (once-and-for-all voting), the contribution rate preferred by a middle-aged, $j$-type voter is solved as follows. First, differentiate (16) subject to (1) - (3), (4), and (14). Using the envelope theorem, multiplying by $1 / \widehat{l\left(\tau_{t}\right)}$, and inserting (A.4) yields

$$
-a_{j, t}^{m}\left(1-\frac{1}{1+r} \theta \chi\right)+\left[\theta \chi a_{j, t-1}^{y}+\frac{1}{1+r} \frac{1-\theta}{n_{t-1}} \omega_{t+1}\right]\left(1-\tau_{t} \frac{1-\frac{\theta \chi}{1+r}}{1-\tau_{w}-\tau_{t}\left(1-\frac{\theta \chi}{1+r}\right)} \gamma\right)
$$

Rearranging (A.7) and noting the non-negativity constraint, the preferred contribution rate of middle-aged voters belonging to the ability group $j$ is

$$
\tau_{j, t}^{m}=\max \left\{\frac{\left(1-\tau_{w}\right)}{\left(1-\frac{\theta \chi}{1+r}\right)} \frac{-a_{j, t}^{m}\left(1-\frac{1}{1+r} \theta \chi\right)\left[\theta \chi a_{j, t-1}^{y}+\frac{1}{1+r} \frac{1-\theta}{n_{t-1}} \omega_{t+1}\right]^{-1}+1}{-a_{j, t}^{m}\left(1-\frac{1}{1+r} \theta \chi\right)\left[\theta \chi a_{j, t-1}^{y}+\frac{1}{1+r} \frac{1-\theta}{n_{t-1}} \omega_{t+1}\right]^{-1}+1+\gamma}, 0\right\}
$$

The old maximize $P_{t}$ subject to (14). Multiplying by $1 / \widehat{l\left(\tau_{t}\right)}$, using (A.4) and reorganizing gives

$$
\left(1-\tau_{t} \frac{1-\frac{\theta \chi}{1+r}}{1-\tau_{w}-\tau_{t}\left(1-\frac{\theta \chi}{1+r}\right)} \gamma\right) \omega_{t}=0
$$

The preferred contribution rate of the old is given by

$$
\tau_{j, t}^{o}=\min \left\{\frac{\left(1-\tau_{w}\right)}{\left(1-\frac{\theta \chi}{1+r}\right)(1+\gamma)}, 1\right\} .
$$

Given by (A.6), (A.8) and (A.10), the preferred contribution rate of any voter group is weakly decreasing in $\tau_{w}$ and $\gamma$.

(ii) By inspecting (A.6) and (A.8) the preferred contribution rates of the young and middleaged voters are non-monotonic in $\theta$, while - following (A.10) - the preferred contribution rate of the old is weakly increasing in $\theta$.

\section{References}

[1] Blondal, S. and Scarpetta, S. (1998). The retirement decisions in OECD countries. OECD W.P. 
[2] Boadway, R.W. and D. E. Wildasin (1989), "A Median Voter Model of Social Security", International Economic Review, 30, 307-328.

[3] Boldrin, M. and A. Rustichini (2000), "Political Equilibria with Social Security", Review of Economic Dynamics, 3, 41-78.

[4] Browning, E. (1975), "Why the Social Insurance Budget is too Large in a Democratic Society", Economic Inquiry, 13, 373-88.

[5] Casamatta, G., H. Cremer, and P. Pestieau (2000), "The Political Economy of Social Security", Scandinavian Journal of Economics, 102, 503-522.

[6] Conde Ruiz, I. and P. Profeta (2004), "The Redistributive Design of Social Security Systems", Working Paper, Universitat Pompeu Fabra, FEDEA and The Pension Institute.

[7] Cooley, T.F. and J. Soares (1999), "A Positive Theory of Social Security Based on Reputation", Journal of Political Economy, 107, 135-160.

[8] Disney, R. (2004), "Are Contributions to Public Pension Programmes a Tax on Employment", Economic Policy, 39, 267-311.

[9] European Commission Household Panel. Wave 1997.

[10] EUROSTAT, Statistics.http:/europa.eu.int/comm/eurostat/newcronos.

[11] Fenge, R., A. Gebauer, C. Holzner, V. Meier and M. Werding (2003), "Old-Age Provision Around the World: Revenues, Benefits, and Taxation" (in German), ifo-Beiträge zur Wirtschaftsforschung, No. 10, Munich.

[12] Galasso, V. and P. Profeta (2002), "The Political Economy of Social Security: A Survey", European Journal of Political Economy, 18, 1-29.

[13] Immervoll, H., H. Kleven, C.T. Kreiner, and E. Saez (2004), "Welfare Reforms in European Countries: A Microsimulation Analysis", CEPR Discussion Paper No. 4324, London.

[14] Koethenbuerger, M., P. Poutvaara, and P. Profeta (2005), "Why are More Redistributive Social Security Systems Smaller? A Median Voter Approach, CESifo WP \# 1397, Munich.

[15] Krueger, A.B. and B.M. Meyer (2002), "Labor Supply Effects of Social Insurance", Handbook of Public Economics, vol. 4, 2327-2392, North-Holland.

[16] Mulligan, C. and X. Sala-i-Martin (2004), "Internationally Common Features of Public Old-Age Pensions, and Their Implications for Models of 
the Public Sector", Advances in Economic Analysis \& Policy, 4, Article 4. http://www.bepress.com/bejeap/advances/vol4/iss1/art4

[17] Nicoletti, C. and F. Peracchi (2001), "Aging in Europe: What Can We Learn from the Europanel?" in T. Boeri, A. Börsch-Supan, A. Brugiavini, R. Disney, A. Kapteyn and F. Peracchi (eds), Pensions: More information, Less ideology. Kluwer, Dordrecht.

[18] OECD (2000), Taxing Wages, Paris.

[19] OECD (2004), OECD in Figures, Paris.

[20] OECD (2005), Pensions at a Glance. Public policies across OECD countries. Paris

[21] Saez, E. (2002), "Optimal Income Transfer Programs: Intensive versus Extensive Labor Supply Responses", Quarterly Journal of Economics, 117, 1039-1073.

[22] Sinn, H.-W. and S. Uebelmesser (2002), "Pensions and the Path to Gerontocracy in Germany", European Journal of Political Economy, 19, 153-158.

[23] Tabellini, G. (2000), "A Positive Theory of Social Security", Scandinavian Journal of Economics, 102, 523-545. 
Table 1: Data

\begin{tabular}{||l|r|r|c|c|l||}
\hline \hline \multicolumn{1}{|c|}{ Country } & $\eta(\%)$ & $g(\%)$ & $\theta$ & $\tau_{w}$ & effective contribution rate $\tau_{\text {eff }}$ \\
\hline Austria & 1.30 & 2.10 & 0.793 & 0.098 & 34.8 \\
\hline France & 1.39 & 2.00 & 0.536 & 0.134 & 27.7 \\
\hline Germany & 1.76 & 1.60 & 0.771 & 0.215 & 22.4 \\
\hline Greece & 0.52 & 3.00 & 0.957 & 0.022 & 57.7 \\
\hline Italy & 1.62 & 1.80 & 0.960 & 0.193 & 40.0 \\
\hline Portugal & 0.78 & 2.50 & 0.689 & 0.067 & 35.4 \\
\hline Spain & 0.91 & 3.00 & 0.870 & 0.121 & 45.0 \\
\hline UK & 2.04 & 1.80 & 0.304 & 0.158 & 23.7 \\
\hline
\end{tabular}

Source: $\eta$ : authors' calculations from the European Community Household Panel. g: taken from EUROSTAT. $\theta$ taken from OECD (2005) as (1-progressivity index). $\tau_{w}$ taken from OECD Taxing Wages 2000 (average tax rate, excluding social security contributions, for a single person with no children earning average income). $\tau_{\text {eff }}$ taken from Disney (2004).

Table 2. Data on productivity levels

\begin{tabular}{|c|c|c|c|c|c|}
\hline & $\begin{array}{l}\text { Very low } \\
\text { income }\end{array}$ & $\begin{array}{l}\text { Low } \\
\text { income }\end{array}$ & $\begin{array}{l}\text { Intermediate } \\
\text { income }\end{array}$ & High income & $\begin{array}{l}\text { Very high } \\
\text { income }\end{array}$ \\
\hline \multicolumn{6}{|c|}{ Austria } \\
\hline Young & 0.422 & 0.703 & 0.859 & 1.0149 & 1.377 \\
\hline Middle-aged & 0.613 & 0.88 & 1.0834 & 1.396 & 1.883 \\
\hline \multicolumn{6}{|c|}{ France } \\
\hline Young & 0.354 & 0.622 & 0.768 & 0.999 & 1.451 \\
\hline Middle-aged & 0.539 & 0.783 & 1.023 & 1.364 & 2.098 \\
\hline \multicolumn{6}{|c|}{ Germany } \\
\hline Young & 0.375 & 0.736 & 0.895 & 1.076 & 1.456 \\
\hline Middle-aged & 0.579 & 0.848 & 1.019 & 1.262 & 1.858 \\
\hline \multicolumn{6}{|c|}{ Greece } \\
\hline Young & 0.338 & 0.617 & 0.777 & 1.021 & 1.514 \\
\hline Middle-aged & 0.397 & 0.793 & 1.13 & 1.446 & 2.129 \\
\hline \multicolumn{6}{|c|}{ Italy } \\
\hline Young & 0.407 & 0.705 & 0.862 & 1.031 & 1.341 \\
\hline Middle-aged & 0.616 & 0.9207 & 1.133 & 1.353 & 1.774 \\
\hline \multicolumn{6}{|c|}{ Portugal } \\
\hline Young & 0.346 & 0.564 & 0.704 & 0.907 & 1.797 \\
\hline Middle-aged & 0.411 & 0.677 & 0.891 & 1.284 & 2.727 \\
\hline \multicolumn{6}{|c|}{ Spain } \\
\hline Young & 0.249 & 0.554 & 1.509 & 0.945 & 1.573 \\
\hline Middle-aged & 0.485 & 0.839 & 1.145 & 1.571 & 2.371 \\
\hline \multicolumn{6}{|c|}{ UK } \\
\hline Young & 0.257 & 0.715 & 0.905 & 1.164 & 1.725 \\
\hline Middle-aged & 0.213 & 0.765 & 1.003 & 1.272 & 2.037 \\
\hline
\end{tabular}


Table 3: Results

\begin{tabular}{|c|c|c|c|c|}
\hline & & \multicolumn{2}{|c|}{$r=0.05$} & \\
\hline & & $\gamma=2$ & $\gamma=1.5$ & \\
\hline Country & $\theta$ & $\tau$ & $\tau$ & median voter \\
\hline Austria & 0.793 & 0.458 & 0.569 & middle-aged, high-income \\
\hline France & 0.536 & 0.275 & 0.342 & middle-aged, high-income \\
\hline Germany & 0.771 & 0.386 & 0.474 & middle-aged, very high-income \\
\hline Greece & 0.957 & 0.723 & 0.884 & middle-aged, high-income \\
\hline Italy & 0.96 & 0.580 & 0.714 & middle-aged, very high-income \\
\hline Portugal & 0.689 & 0.350 & 0.435 & middle-aged, high-income \\
\hline Spain & 0.87 & 0.690 & 0.738 & middle-aged, high-income \\
\hline UK & 0.304 & 0.245 & 0.343 & middle-aged, high-income \\
\hline \multicolumn{2}{|c|}{$\operatorname{corr}(\theta, \tau)$} & 0.866 & 0.867 & \\
\hline \multicolumn{2}{|c|}{$\operatorname{corr}\left(\tau, \tau_{e f f}\right)$} & 0.899 & 0.91 & \\
\hline
\end{tabular}

